\title{
O HIATO (IN)TRANSPONÍVEL ENTRE FATOS E VALORES: UMA ABORDAGEM A PARTIR DO REALISMO-COGNITIVO DE THOMAS SCANLON
}

\author{
Lucas Mateus Dalsotto ${ }^{1}$ \\ Universidade Federal de Santa Maria (UFSM)
}

\begin{abstract}
RESUMO:
No decorrer dos últimos três séculos desenvolveu-se em ética uma dicotomia entre fatos e valores cuja influência ainda hoje gera discussões. Nesse ensejo, a intenção deste artigo é propor, a partir do realismo-cognitivo de Scanlon, uma leitura alternativa a respeito dessa dicotomia estabelecida entre fatos e valores. Em geral, boa parte desse problema deve-se ao motivo de que as reivindicações do domínio normativo são muitas vezes avaliadas a partir da ótica da ciência (domínio não-normativo), isto é, da visão científica de mundo (scientific view of the world). Mas conforme buscarei sustentar, é preciso que o domínio normativo seja avaliado a partir dos padrões de seu próprio domínio cujo elemento básico é a relação ser uma razão para (being a reason for). Verdades normativas são irredutíveis na medida em que são determinadas por certos padrões de resposta dentro de um domínio específico em si mesmo, o que no campo normativo é realizado pela ideia de reivindicações normativas puras. Assim, partindo-se do pressuposto de que verdades normativas são irredutíveis e que, nesse caso, podem ser verdadeiras ou falsas, o melhor modo de compreendê-las é a partir da relação $\mathrm{R}(p, x, c, a)$, sendo $p$ um fato, $x$ um agente, $c$ um conjunto de condições e circunstâncias e $a$ uma ação ou atitude. A partir desse padrão constituído no interior do domínio normativo, a relação R estabelece que $p$ é uma razão para um agente $x$ realizar uma ação ou atitude $a$ no conjunto de condições e circunstâncias $c$. se isto estiver certo, então, ao menos em termos normativos, o hiato entre fato/valor parece ser transponível.
\end{abstract}

PALAVRAS-CHAVE: Realismo-cognitivo; Dicotomia; Fato/Valor; Thomas Scanlon.

\footnotetext{
${ }^{1}$ Doutorando pelo Programa de Pós-Graduação em Filosofia da Universidade Federal de Santa Maria (UFSM), Rio Grande do Sul - Brasil. E-mail: lmdalsotto@ hotmail.com.
} 


\title{
THE (UN)BRIDGEABLE GAP BETWEEN FACTS AND VALUES: AN APPROACH FROM THOMAS SCANLON'S COGNITIVE-REALISM
}

\begin{abstract}
:
Over the past three centuries developed into ethics a dichotomy between facts and values whose influence still generates discussions. In this occasion, the intention of this article is to propose, from the cognitiverealism Scanlon, an alternative reading about this established dichotomy between facts and values. In general, much of this problem is due to the reason that the claims of the normative domain are often evaluated from the perspective of science (non-normative field), that is, the scientific world view. But as I will seek support, we need the regulatory domain is evaluated from the standards of his own domain whose basic element is the relationship be one reason (the reason for being). Normative truths can not be reduced to the extent that is determined by certain response patterns within a specific domain itself, which in the legal field is carried out by the idea of pure normative claims. Thus, starting from the assumption that normative truths are irreducible and in this case, can be true or false, the best way to understand them is from the relationship $\mathrm{R}(p, x, c, a)$, where $\mathrm{p}$ a fact, $x$ an agent, $c$ a set of conditions and circumstances and to an action or attitude. From this standard constituted within the normative domain, the relation $\mathrm{R}$ states that $p$ is a reason for an agent $x$ perform an action or attitude $a$ to the set of conditions and circumstances $c$. Therefore, at least in normative terms, the gap between fact/value seems to be transposed.
\end{abstract}

KEYWORDS: Cognitive-Realism; Dichotomy; Fact/Value; Thomas Scanlon.

Introdução

Em geral, no decorrer da primeira metade do século XX, difundiu-se amplamente na academia filosófica o dogma segundo o qual julgamentos de valores são profundamente diferentes de julgamentos factuais, de modo que aqueles primeiros são subjetivos e instáveis de uma forma que estes últimos não o são. Assim, essa dicotomia entre fato/valor tornou-se por algum tempo um campo pacífico de discussão a ponto de ser aceita e recitada como um truísmo incontroverso nos departamentos de filosofia ${ }^{2}$. O pressuposto era de que nenhuma afirmação normativa poderia ser derivada de qualquer conjunto de afirmações não-normativas via implicação lógica ou conceitual sem que já nas premissas houvesse alguma afirmação normativa.

${ }^{2}$ Ver LONG, 2006. p. 125-131. 
No entanto, há poucas décadas, os principais suportes dessa dicotomia entre fato/valor começaram a ser fortemente atacados por alguns autores, dentre os quais Hilary Putnam (2004), John Searle (1969) e Thomas Scanlon $(1998 ; 2014)$. Os primeiros dois realizaram críticas bastante fortes em direção a esta dicotomia. Tanto o é que Putnam ${ }^{3}$ chega a enunciar o colapso da mesma. No entanto, como adiante buscarei expor, a proposta do presente texto tem um escopo mais limitado do que as críticas realizadas por Putnam e Searle. Acredito que as ideias de Scanlon podem esclarecer bastante o problema em questão, uma vez que ele contesta especificamente o tipo de derivação que está em questão entre afirmações normativas e nãonormativas e sustenta que é preciso "caracterizar mais claramente as classes de afirmações de ambos os lados do hiato (gap)" (SCANLON, 2014, p. 33). Seu ponto não está em discutir os problemas lógicos vinculados a este debate, assim como Putnam e Searle estão, mas tão somente em dizer que, ao menos em termos normativos, é possível transpor este hiato.

Dada esta problemática e seguindo os passos de Scanlon em seu livro Being Realistic about Reasons, buscarei sustentar que há uma indissociabilidade entre fatos e valores na medida em que se compreende a relação entre normativo e não-normativo em termos da relação de algo ser uma razão para alguém fazer alguma coisa em dadas circunstâncias no interior de um domínio. Tal proposta toma como pano de fundo uma proposta metaética cognitivo-realista segundo a qual verdades sobre razões são fundamentais em um senso que elas não podem ser reduzidas ou identificadas com verdades naturais, tal como as verdades a respeito do mundo natural dos objetos, das causas e dos efeitos físicos. Verdades normativas são irredutíveis na medida em que são determinadas por certos padrões de resposta dentro de um domínio específico em si mesmo. Do mesmo modo que verdades matemáticas exigem-nos simplesmente que pensemos sobre determinadas questões de maneira correta, assim também nos exigem as verdades normativas.

Para levar adiante esta proposta, apresentarei, a partir de Hume, a problematização clássica e suas possíveis interpretações a respeito da dicotomia entre fato/valor (seção 2) e então sugerirei que é um erro avaliar o domínio normativo a partir visão científica de mundo (scientific view of the world) (seção 3). Seguindo os passos de Scanlon, sustentarei que as reivindicações normativas devem ser compreendidas sempre no interior de seu próprio domínio e segundo os padrões deste (seção 4). Por fim, buscarei mostrar que, a partir da ideia de reivindicações normativas puras, é possível

\footnotetext{
${ }^{3}$ Putnam (2004) defende que toda vez que utilizamos conceitos como cruel e corajoso para identificar determinadas práticas, estamos fazendo uso de conceitos éticos 'thick', para utilizarmos os termos de Bernard Williams. Tais conceitos vinculam aspectos descritivos e valorativos em um mesmo juízo, de modo que eles não podem ser compreendidos separadamente.
} 
eliminar o hiato entre fato/valor ao menos em termos normativos (seção 5) e esboçarei um breve resumo da proposta do presente texto (seção 6).

\section{A questão da não-derivabilidade de valores de fatos}

Historicamente, o problema entre fatos e valores, ou ainda, da impossibilidade de derivar proposições normativas de proposições nãonormativas sempre esteve associado à a filosofia de Hume (2001, p. 509) e mais especificamente à sua célebre passagem do Tratado onde se lê

[...] surpreendo-me ao ver que, em vez das cópulas proposicionais usuais, como é e não é, não encontro uma só proposição que não esteja conectada a outra por um deve ou não deve. Essa mudança é imperceptível, porém da maior importância. Pois, como esse deve ou não deve expressa uma nova relação ou afirmação, esta precisaria ser notada e explicitada; ao mesmo tempo, seria preciso que se desse uma nova razão para algo que parece inteiramente inconcebível, ou seja, como essa nova relação pode ser deduzida de outras inteiramente diferentes.

Em geral, esse excerto tem sido utilizado para fundamentar a tese de que existem duas classes distintas de afirmações (factuais e normativas) cuja relação entre ambas é tal que nenhum conjunto de premissas factuais poderia implicar tanto lógica quanto conceitualmente (derivar) uma conclusão normativa. Mas Macintyre (1970, p. 170), ao referir-se a esta passagem, sustenta que uma leitura atenta da mesma não esclarece se Hume está dizendo que o passo de derivação de um "ser para um deve ser exige um grande cuidado ou se esse passo é logicamente impossível". Ou seja, não está claro se Hume chega à conclusão de que a maioria das derivações do ser para o dever ser são falácias ou se elas são sempre necessariamente falácias. Tendo em vista a sua filosofia moral como um todo, parece que a primeira afirmação é preferível, uma vez que o próprio Hume (2001, p. 520) realiza derivações do ser para o dever ser.

Suponhamos que uma pessoa tenha me emprestado uma soma de dinheiro, sob a condição de que eu lhe retribuísse essa soma em alguns dias; suponhamos, também, que, no fim do prazo combinado, ela me peça o dinheiro de volta. Pergunto: que razão ou motivo tenho para devolver-lhe o dinheiro? Dir-se-á, talvez, que meu respeito pela justiça e minha repulsa à vilania e à desonestidade são para mim razões suficientes, se possuo um mínimo de honestidade ou senso de dever e de obrigação.

No entanto, é preciso dizer que o fragmento acima vai de encontro à ideia de Macintyre apenas se dermos a devida atenção, por assim dizer, à teoria das virtudes presente na teoria de Hume. O que Hume parece dizer é 
que a natureza humana é constituída de determinados princípios antropológicos fundamentais, tais como, a apetite geral pelo bem e aversão ao mal, a simpatia, a compaixão e assim por diante. Isso parece evidente quando ele afirma que "tais sentimentos estão tão enraizados em nossa constituição e caráter que, a não ser que a mente humana esteja completamente transtornada pela doença e loucura, seria impossível extirpálos e destruí-los" (HUME, 2001, p. 514).

Destarte, se essa argumentação está correta, então é possível defender a ideia de que, de certo modo, a primeira interpretação de Macintyre a respeito da filosofia moral de Hume é mais adequada. E desse modo, na medida em que se compreende a passagem de Hume anteriormente citada como uma afirmação de que o hiato entre fato/valor não é instransponível, mas que apenas a passagem de um domínio a outro deve ser realizada cuidadosamente, então a tese de Scanlon parece seguir-se.

\section{A dicotomia entre fato/valor: um problema de pressupostos}

De qualquer modo, a despeito de qual seja a correta interpretação a ser dada à passagem anteriormente citada de Hume, o que é preciso que se tenha atenção é que as reivindicações dos filósofos sobre o hiato ( $g a p)$ entre fatos e valores têm geralmente tomado como ponto de partida a caracterização da classe das afirmações não-normativas e não o contrário. Os juízos normativos são contrastados e avaliados com relação à caracterização da classe das afirmações não-normativas que se tem. Se vemos a física como a única teoria verdadeira e que por isso todas as demais áreas do conhecimento devam tomá-la como parâmetro de avaliação de seus respectivos objetos de estudo, então tendemos a considerar subjetiva todas as discussões e julgamentos que não possam ser explicadas a partir do quadro conceitual fisicalista (MARINHO, 1997).

Por isso, pode-se dizer que um dos motivos que levou à sedimentação da dicotomia entre fatos e valores foi exatamente tomar como ponto de partida para o debate a caracterização da classe do domínio nãonormativo, ou mais especificamente, a visão científica de mundo (scientific view of the world). A ciência, no sentido estrito do termo, é uma maneira de compreender o mundo natural. Suas conclusões representam a melhor compreensão do que o mundo contém e do que acontece nele. Aceitar a ciência nestes termos implica em rejeitar afirmações sobre o mundo que são incompatíveis com a ciência. Mas aceitar a "visão científica do mundo natural não significa aceitar a visão que somente afirmações significativas com determinados valores de verdade são afirmações sobre o mundo natural" (SCANLON, 2014, p. 18).

No campo metaético, John Mackie é um exemplo de filósofo que compreende a normatividade a partir de uma visão científica de mundo (scientific view of the world). $\mathrm{O}$ argumento da estranheza (queerness) de 
Mackie baseia-se em duas ideias principais: uma metafísica e outra epistemológica. A primeira afirma que a concepção de propriedade moral é um tipo de propriedade muito rara, de tal forma que sua instanciação nos obriga a postular existência de qualidades e relações de um tipo muito estranho, completamente diferente de qualquer coisa que exista no universo. A segunda, por sua vez, afirma que, a fim de rastrearmos tais propriedades estranhas, seria necessário que tivéssemos alguma faculdade especial de percepção ou intuição moral que fosse, ao mesmo tempo, diferente de todas as nossas maneiras habituais de conhecer as coisas (HUSSAIN; SHAH, apud, BAGNOLI, 2013).

Segundo Mackie (1977, p. 38), "se valores objetivos existissem, então eles deveriam ser entidades, qualidades ou relações de um tipo muito estranho (queer), completamente diferente de qualquer coisa mais no universo". Desse modo, falar que propriedades morais existem requer sustentar a existência de prescrições objetivas e isso Mackie pensa ser falso, uma vez que propriedades morais objetivas não existem. Sua ideia é de que nossos compromissos ontológicos deveriam ser restringidos para as coisas do mundo físico das partículas e dos planetas que são descritos pela ciência. Esta tese está atrelada ao pressuposto de que, se alguém pretende defender a ideia de que verdades normativas irredutíveis existem, então isso implica que esse indivíduo encontrará uma série de problemas de ordem ontológica.

Mas não me parece que isso seja necessariamente verdadeiro. Minha objeção com relação ao argumento de Mackie é de que o ponto de partida que ele toma para discutir questões normativas não é o adequado. Quando se toma como ponto de partida a visão científica de mundo (scientific view of the world) como critério de avaliação de outros domínios, as únicas teorias que interessam são apenas aquelas que convergem com a visão científica de mundo e com a referência sensorial deste.

Nesse caso, de antemão, questões normativas estão desconsideradas da discussão na medida em que elas não estão de acordo com o critério de avaliação estabelecido como sendo verdadeiro, a saber, a visão científica de mundo (scientific view of the world). Contudo, não apenas as questões normativas estariam desconsideradas da discussão. Conforme Scanlon, questões a respeito da matemática e da lógica pareceriam estar excluídas desse debate tanto quanto as normativas. Por isso, a ideia de que existem verdades normativas irredutíveis não exige compromissos ontológicos com "algumas entidades especiais", mas apenas compromissos normativos compreendidos dentro de um domínio (SCANLON, 2014). Assim, a discussão que se segue tomará como ponto de partida a classe das afirmações normativas, invertendo o processo até então empregado pelos círculos acadêmicos de filosofia, e buscará explicar porque a ideia de domínio é importante para essa discussão. 


\title{
Uma proposta metaética cognitivo-realista: a ideia de domínio
}

De acordo com Scanlon, a melhor forma de se conceber a dicotomia entre fato/valor diz respeito a uma leitura que não privilegie a ciência no debate, mas que tome como base uma ampla gama de domínios, incluindo a matemática, a moral, a razão prática e a própria ciência. Afirmações no interior desses domínios são capazes de verdade ou falsidade e os valores de verdade das afirmações de um determinado domínio, na medida em que não entram em conflito com outros domínios, são estabelecidos por padrões de resposta destes (SCANLON, 2014). Questões matemáticas são estabelecidas por razões matemáticas assim como questões normativas são estabelecidas por razões normativas e questões científicas são estabelecidas por razões científicas. Mas o que Scanlon exatamente quer dizer com o termo domínio?

Um primeiro aspecto diz respeito à ideia de domínio. $\mathrm{O}$ domínio normativo não é um reino distinto da realidade. Coisas do mundo natural, assim como pessoas e suas ações, possuem propriedades normativas e muitas reivindicações normativas são reivindicações sobre essas coisas. Desse modo, ele é mais bem compreendido em termos do tipo de reivindicações que ela envolve, e por isso em termos de conceitos dos quais ela envolve, "tais como números, conjuntos, objetos físicos, razões ou ações moralmente corretas" (SCANLON, 2014, p. 19).

Um segundo ponto concerne à ideia da existência de padrões para responder questões dentro de um domínio.

\begin{abstract}
Existem padrões matemáticos para responder questões matemáticas, padrões científicos para responder questões empíricas sobre o mundo físico e formas de razões práticas para responder questões sobre o que nós temos razões para fazer. Esses padrões tipicamente consistem, em parte, de princípios substantivos sobre o domínio, tal como axiomas matemáticos, princípios morais e generalizações científicas. [...] Por exemplo, pensar sobre o conceito de conjunto pode levar a mudanças na aceitação dos axiomas da teoria dos conjuntos e pensar sobre as ideias de moralmente correto e errado pode levar a mudanças na aceitação de teorias e princípios morais (SCANLON, 2014, p. 20).
\end{abstract}

Dito de outro modo, as reivindicações que as pessoas fazem a respeito daquilo que é moralmente correto e errado pressupõe a existência de padrões que qualquer um teria boas razões para tomá-los como parâmetro para conduzir suas próprias ações ou ainda para contestar o que os outros fazem. A afirmação de que questões acerca de um dado domínio deveriam ser determinadas pela melhor maneira de pensar sobre eles toma como pano de fundo a ideia de que existem certos padrões de correção que definem a maneira correta de se pensar determinados assuntos. No caso normativo, o 
elemento básico do domínio é a relação ser uma razão para (being a reason for $)^{4}$.

Partindo-se do suposto de que verdades normativas são irredutíveis e que, nesse caso, podem ser verdadeiras ou falsas, o melhor modo de compreendê-las é a partir da relação $\mathrm{R}(p, x, c, a)$, sendo $p$ um fato, $x$ um agente, $c$ um conjunto de condições e circunstâncias e $a$ uma ação ou atitude. A partir desse padrão constituído no interior do domínio normativo, a relação $\mathrm{R}$ estabelece que $p$ é uma razão para um agente $x$ realizar uma ação ou atitude $a$ no conjunto de condições e circunstâncias $c$. Se mantivermos a estrutura de $\mathrm{R}$ inalterada, podemos sustentar, por exemplo, que o fato de que facas são instrumentos afiados e cortantes é uma razão para que, salvo em casos muitos específicos, qualquer indivíduo $x$ não pressionasse sua mão contra o fio de uma faca.

Os termos $x$ e $a$ são fixados a partir de dentro da relação R. Eles funcionam como elementos 'independentes e invariáveis' dos padrões do domínio normativo. No entanto, os termos $p$ e $c$ precisam ser compreendidos de um modo muito específico na relação $\mathrm{R}$, caso contrário, a defesa de uma proposta metaética cognitivo-realista sobre razões não faz sentido. Tais elementos são, por assim dizer, "dependentes e variáveis", ou seja, as razões pelas quais um determinado indivíduo $p$ realiza uma ação $x$ podem ser inúmeras e o conjunto de condições e circunstâncias nas quais ele realiza a ação $x$ também o podem.

Compreendida assim, a relação $\mathrm{R}$ parece ainda não ser capaz de determinar de modo claro os padrões de resposta para determinar a existência de verdades normativas irredutíveis. Por isso, uma importante cláusula de nosso argumento é que "alguma coisa é uma razão para um agente somente se é também uma razão para qualquer outro agente em similares circunstâncias" (SCANLON, 2014, p. 32-3). Como dito anteriormente, essa cláusula exige que as circunstâncias $(c)$ nas quais alguma coisa é uma razão para alguém $(x)$, possam sê-la também para $x$, $x$ ', $x_{n .}$. Essas são, nos termos de Thomas Nagel, o que podemos chamar de razões objetivas ${ }^{5}$ ou ainda, nos termos de Scanlon, reivindicações normativas puras ${ }^{6}$.

\footnotetext{
${ }^{4}$ Há um caráter fortemente relacional quando falamos a respeito de razões, pois elas somente o são em relação a um agente.

${ }^{5}$ Segundo Nagel (1996), existem duas formas de classificar os tipos de razão que levam um determinado indivíduo a agir, a saber: (i) as razões relativas ao agente e (ii) as razões neutras em relação ao agente. O raciocínio que explicita esse primeiro tipo de razões pode ser, por exemplo, o seguinte: se $x$ tem uma razão para realizar a ação $a$, pressupondo que a realização de $a$ trar-lhe-á algo agradável, então $x$ deve realizar $a$. As ações recomendadas aqui são antes de tudo para o bem do próprio agente e para a sua realização pessoal (pressupondo que ele saiba de fato em que consiste a sua realização). O segundo tipo de razões origina-se de valores comuns e impessoais. A exigência das razões neutras em relação ao agente é de que a ação a ser realizada deve passar um extenso escrutínio de avaliação, independente das vontades e desejos de um agente particular. O pressuposto é
} 
Um último aspecto a ser abordado com respeito à ideia de domínio refere-se aos conflitos de afirmações entre diferentes domínios, no caso, entre fatos/valores. A tese de que o valor de verdade de afirmações em um domínio é corretamente estabelecido por padrões internos aplica-se apenas ao que chamaremos de reivindicações puras de um domínio e não a reivindicações mistas. Explique-se.

As reivindicações puras de um domínio são internas a este, isto é, elas não se vinculam diretamente a outro domínio e nem dependem de fatos contingentes sobre o mundo. Elas são independentes dos agentes e têm como função atribuir significado normativo a fatos não-normativos sem com isso se ligarem necessariamente a eles. Já as reivindicações mistas de um domínio envolvem afirmações normativas puras, mas também fazem ou pressupõem reivindicações sobre fatos naturais. Tais afirmações são familiares nos casos em que são usados os conceitos éticos 'thick' e são elas que realizam a vinculação entre fatos e valores.

Cito Scanlon (2014, p. 20-1)

No caso da teoria dos números e das teorias dos conjuntos, afirmações puras são afirmações que empregam somente conceitos peculiares a esse domínio. No caso das afirmações normativas a questão é mais complicada, uma vez que afirmações normativas fazem reivindicações sobre o significado de fatos e propriedade naturais. Então, por exemplo, a reivindicação que uma certa ação é moralmente errada pode envolver não somente a reivindicação que alguma ação que tem determinadas consequências seria errada, mas também que essa ação atualmente tem essas consequências. A verdade de tal reivindicação dependeria, portanto, tanto de razões empíricas quanto de morais.

\section{Eliminando o hiato entre fatos/valores no domínio normativo}

Mesmo admitindo-se a ideia de que a existência de verdades normativas irredutíveis compreendidas no interior de um domínio não gera implicações ontológicas preocupantes ou incômodas, parece que a maior dificuldade ainda permanece em explicar a relação entre fatos normativos e fatos naturais. É preciso ainda dizer por que é possível fazer a afirmação de que, por exemplo, o fato de que facas são instrumentos afiados e cortantes é uma razão para que, salvo em casos muitos específicos, qualquer indivíduo $x$ não pressionasse sua mão contra o fio de uma faca. Embora pareça

que as prescrições normativas desse segundo tipo se auto impõem como necessárias frente à vontade dos agentes. Em certa medida, Scanlon já havia endossado a posição de Nagel quando fixou como critério de avaliação moral a ideia segunda a qual cada indivíduo deve ser capaz de "justificar as próprias ações aos outros por razões que ninguém poderia razoavelmente rejeitar" (SCANLON, apud, SEN; WILLIAMS, 1982. p. 116).

${ }^{6} \mathrm{Na}$ seção 5 esclarecerei o que elas significam. 
razoável que, em geral, as pessoas concordem e empreguem essa frase em determinadas situação, do ponto de vista factual e normativo, essa passagem entre fato/valor não parece possível de ser feita.

Ora, nosso pressuposto é de que reivindicações normativas não se referem apenas a um tipo de reino especial, mas são, em um importante sentido, sobre o mundo natural. Elas atribuem significado normativo a fatos naturais (SCANLON, 2014). No entanto, isso não significa dizer que verdades normativas não sejam distintas de verdades não-normativas. Do ponto de vista lógico, a afirmação de que verdades normativas implicam logicamente afirmações não-normativas é difícil de ser aceita e causa uma série de problemas que não estou disposto a enfrentar.

Meu ponto é mais simples. Se por um lado verdades normativas não implicam lógica ou conceitualmente verdades não-normativas, por outro elas variam quando fatos naturais variam (covariância) e não variam muito quando fatos naturais permanecem os mesmos (superveniência). Essas relações precisam ser explicadas. Por isso, minha argumentação restringe-se apenas em afirmar que, no que diz respeito ao domínio normativo, há uma relação entre fato/valor que não parece justificar a dicotomia estabelecida entre ambos os domínios. Daí a necessidade de esclarecer que tipo de derivação está em questão entre valores e fatos e de que modo esses domínios se relacionam.

A ideia de que existe um hiato entre fatos e valores decorre de que comumente as pessoas fazem inferências de fatos não normativos para conclusões normativas. Por exemplo,

(i) Se Carlos não deixar sua casa em chamas agora, ele irá morrer.

Disso parece seguir-se que

(ii) Carlos tem uma razão para deixar sua casa em chamas agora.

Se há de fato então um hiato ( $\mathrm{gap}$ ) lógico entre fatos e valores, então como nós podemos facilmente realizar a todo tempo esse salto? A resposta é que embora (ii) não seja implicado (lógica ou conceitualmente) por (i), ele, no entanto, segue-se de (i) com a adição de

(iii) A situação de Carlos é tal que o fato que fazer a é necessário para ele evitar morrer agora se configura como uma razão para fazer a.

(iv) Supondo-se, é claro, que Carlos e, de maneira geral, qualquer um não deseja morrer em tais condições $\mathrm{c}$.

Muito embora (iii) ainda seja uma reivindicação normativa mista a respeito da situação atual de Carlos, as condições $c$ poderiam ser tomadas como 
reivindicações que qualquer pessoa em tais circunstâncias, "se plenamente informada e pensando com clareza" (SCANLON ,2014, p. 12), teria razões para fazer aquilo que é necessário para prolongar sua vida, assim como expresso em (iv). Todo aquele que aceitar (iii) e (iv), verá (i) como uma razão para Carlos deixar sua casa em chamas imediatamente. Por isso, o movimento entre fatos não-normativos (i) para fatos normativos (ii) deve ser explicado a partir da adição de uma reivindicação normativa pura (iii). A assertiva (iii) funciona, de certo modo, como uma metanorma, isto é, ela fixa de modo prévio que tipo de conclusão deve-se seguir de (i)

\begin{abstract}
Reivindicações normativas mistas ${ }^{7}$, tal como (ii), desse modo, dependem de reivindicações não-normativas, essa dependência sendo determinada, finalmente, por reivindicações normativas puras. Poderia ser tentador dizer que reivindicações normativas mistas tal como (ii) são verdades em virtude de reivindicações não normativas tal como (i). Mas isso seria enganador na medida em que isso sugere que elas são verdadeiras somente em virtude da verdade daquelas reivindicações, negligenciando a regra das reivindicações normativas puras em determinação de como esse é o caso (SCANLON, 2014, p. 39-40).
\end{abstract}

Reivindicações normativas puras não dependem de reivindicações não-normativas e são inclusive independentes de nós na medida em que razões têm determinadas respostas no interior do domínio normativo. Fatos normativos mistos dependem de fatos não-normativos, e estes dependem de uma questão normativa, a qual é determinada pela verdade das reivindicações normativas puras. Assim, o hiato entre fatos e valores pode ser transposto sem maiores problemas e os fenômenos da covariância e superveniência podem ser melhores entendidos na medida em que não se compreende esse hiato em termos de implicação lógica ou conceitual.

\title{
Considerações finais
}

Dada a profunda e controversa dicotomia estabelecida entre fatos e valores no decorrer dos últimos séculos, a proposta do presente escrito foi demonstrar que, se as idéias de Scanlon (2014) estão corretas, ao menos em termos normativos, tal dicotomia não parece fazer sentido. Isso porque, em geral, o ponto de partida para a presente discussão sempre foi a classe das afirmações não-normativas, a qual tinha como parâmetro de avaliação a visão científica de mundo (scientific view of the world). No entanto, a partir da proposta metaética cognitivo-realista de Scanlon, a discussão que realizamos tomou como ponto de toque a classe afirmações normativas,

\footnotetext{
${ }^{7}$ Grifos nossos.
} 
invertendo assim, o processo até então empregado pelos círculos acadêmicos de filosofia.

Partindo do pressuposto de que conceitos normativos devem ser compreendidos como conceitos relacionais em termos de razões que alguém tem para realizar determinadas ações em dadas circunstâncias - $\mathrm{R}(p, x, c, a)$ -, é possível dizer então que verdades normativas são irredutíveis de uma forma que elas não podem ser reduzidas ou identificadas com verdades naturais. Cada domínio determina internamente seus padrões de resposta, o que no campo normativo é realizado pelas reivindicações normativas puras. Portanto, se a ideia de que há uma indissociabilidade entre fato/valor está correta, então a dicotomia entre fatos normativos e não-normativos não se aplica ao domínio normativo, pois não se pode estabelecer uma dicotomia entre domínios distintos. Ao menos em termos normativos, o hiato entre fato/ valor parece ser transponível. 


\section{Referências bibliográficas}

HUME, David. Tratado da natureza humana. São Paulo: Editora UNESP, 2001.

HUSSAIN, Nadeem J. Z.; SHAH, Nishi. Meta-ethics and its discontents: a case study of Korsgaard. In; BAGNOLI, Carla. Constructivism in Ethics. New York: Cambrigde University Press, 2013.

LONG, Roderick T. Draft on Hilary Putnam's The Collapse of the Fact/Value Dichotomy and Other Essays. In: Reasons papers. N 28, Spring, 2006. p. 125-131.

MACINTYRE, Alasdair. Historia de la Etica. Buenos Aires: Editoria Paidos, 1970.

MACKIE, John. Ethics: inventing Right and Wrong. Harmondsworth: Penguin Books, 1977.

MARINHO, Maria. S. C. Hilary Putnam e a questão fato-valor. Princípios. Rio Grande do Norte, ano 04, $\mathrm{n}^{\circ} 05$ 1997. p. 187-198.

NAGEL, Thomas. Igualdad y parcialidade. Barcelona: Paidós, 1996.

PUTNAM, Hilary. The collapse of the Fact/Value Dichotomy and Other Essays. Cambridge, MA: Harvard University Press, 2004.

SCANLON, Thomas M. Contratualism and utilitarism. In: SEN, Amartya; WILLIAMS, Bernard (orgs). Utilitarism and beyond. Cambridge: Cambridge University Press, 1982.

. What we owe to each other. Cambridge: Belknap Press of Harvard University Press, 1998.

2014 - Being realistic about reasons. Oxford: Oxford University Press,

SEARLE, John. Speech Acts: An essay in the Philosophy of Language. Cambridge: Cambridge University Press, 1969. 